\title{
Novel compound heterozygous mutations in the SRD5A2 gene from 46,XY infants with ambiguous external genitalia
}

\author{
Felipe Vilchis · Evangelina Valdez $\cdot$ Luis Ramos • \\ Rocio García $\cdot$ Rita Gómez $\cdot$ Bertha Chávez
}

Received: 8 August 2007/Accepted: 27 January 2008/Published online: 19 March 2008

(C) The Japan Society of Human Genetics and Springer 2008

\begin{abstract}
Dihydrotestosterone is crucial for normal development of external genitalia and prostate in the male embryo. Autosomal recessive mutations in the $5 \alpha$-reductase type 2 (SRD5A2) gene disrupt the synthesis of dihydrotestosterone in the urogenital tract and give rise to genetic males with undervirilized external genitalia that may be femalelike or ambiguous. In this study, three unrelated 46,XY children $(0.5,3$, and 8 years old) who presented severe undermasculinization at birth were examined for genetic abnormalities in the SRD5A2 gene. Coding sequence abnormalities were ascertained by exon-specific polymerase chain reaction (PCR), single-stranded conformational polymorphism (SSCP), and sequencing analysis. Functional properties of the mutant alleles were investigated by means of site-directed mutagenesis assays. DNA molecular studies showed that all three patients were compound heterozygotes for SRD5A2 mutations. Patient 1 had a point mutation $547 \mathrm{G} \rightarrow \mathrm{A}$ in exon 3 (G183S) and a novel dinucleotidic mutation 634,635CC $\rightarrow$ TG in exon 4 (P212X). This double change results in premature termination signal (TGA) at codon 212, which predicts the expression of a truncated 211amino acid protein. Patient 2 was the carrier of mutations
\end{abstract}

F. Vilchis · L. Ramos · R. García · B. Chávez $(\bowtie)$

Department of Reproductive Biology,

Instituto Nacional de Ciencias Médicas y Nutrición Salvador

Zubirán, Vasco de Quiroga 15, Del. Tlalpan, México,

DF C.P. 14000, Mexico

e-mail: bachavez@prodigy.net.mx

E. Valdez

Servicio de Endocrinología, CMN 20

de Noviembre ISSSTE, México, DF, Mexico

R. Gómez

Hospital de Pediatría, CMN Siglo XXI, IMSS,

México, DF, Mexico
G115D in exon 3 and S210F in exon 4. Patient 3 had two substitution mutations in exon 1, including a novel $\mathrm{G} \rightarrow \mathrm{C}$ transversion at nucleotide $169(\mathrm{E} 57 \mathrm{Q})$ and a $\mathrm{G} \rightarrow \mathrm{A}$ transition at nucleotide 254 (G85D). In transitory transfection assays, the recombinant cDNAs harboring mutations E57Q and G85D showed residual $5 \alpha$-reductase activity, whereas those with mutations G115D, S210F, and P212X were devoided of activity. In contrast, the G183S substitution affected the catalytic activity of the enzyme by decreasing its affinity for testosterone substrate. We describe six different mutations of the SRD5A2 gene detected in three children with genital ambiguity. These genotypes are consistent with the clinical phenotype of steroid $5 \alpha$-reductase 2 deficiency. Our data suggest that the combined gene variants (E57Q/G85D, G115D/S210F, and G183S/P212X) result in subfunctional or nonfunctional enzymes, causing masculinization defects in these patients. This further underscores that exon 4 of SRD5A2 may be a site prone to inactivating mutations.

Keywords Hypospadias - Genital ambiguity · Male pseudohermaphroditism · Micropenis - DHT . $5 \alpha$-Reductase - Steroid $5 \alpha$-reductase 2 deficiency . 46,XY DSD

\section{Introduction}

The conversion of testosterone (T) to $5 \alpha$-dihydrotestosterone (DHT) is critical for the formation of male external genitalia (penis and scrotum) and prostate in the male embryo. At early stages of fetal development, this irreversible reaction is catalyzed by the $5 \alpha$-reductase type 2 (EC 1.3.99.5), a membrane-bound nicotinamide adenine dinucleotide phosphate, reduced (NADPH)-dependent isoenzyme encoded by the SRD5A2 gene (Andersson et al. 
1991). It is located on chromosome 2 (p23 region) and is comprised of five exons and four introns spanning over $56 \mathrm{~kb}$ of genomic DNA (Labrie et al. 1992). The human isozyme 2 is 254 residues long with a predicted molecular weight of 28,393 . The distribution of hydrophobic amino acids throughout its sequence suggests the existence of at least four putative transmembrane regions. Data from previous studies have shown that single base mutations or the complete deletion of SRD5A2 results in steroid $5 \alpha$-reductase 2 deficiency, a rare disorder of sexual development (Andersson et al. 1991; Wilson et al. 1993; Russell et al. 1994). Affected individuals are karyotypic males who at birth usually present with pseudovagina, perineoscrotal hypospadias, micropenis, and cryptorchid testes (Walsh et al. 1974; Imperato-McGinley et al. 1974). Due to their phenotypic appearance, most of these patients are reared as females. During puberty, significant virilization occurs, and without any therapeutic intervention, masculinization is frequently accompanied by a gender identity change from female to male (Pérez-Palacios et al. 1987; Wilson et al. 1993; Méndez et al. 1995). The phenotypic expression of this entity may be variable depending on the type of mutation and its effect on enzyme activity (Russell and Wilson 1994; Wigley et al. 1994; Sinnecker et al. 1996). To date, more than 40 distinct mutations have been described in subjects bearing the enzyme disorder. Of these, about $60 \%$ have homozygous mutations and the remainder are compound heterozygotes (Chavez et al. 2000; Griffin et al. 2001; Fernandez-Cancio et al. 2004a, b). In addition, there are other cases described in which the affected subjects presented only one mutated allele (Wilson et al. 1996; Nicoleti et al. 2005). We studied the SRD5A2 gene from infants with 46,XY DSD who were born with ambiguity of external genitalia. A total of six distinct heterozygous mutations of SRD5A2 are described, including three new genetic variants detected in exons 1 and 4 .

\section{Patients and methods}

\section{Patients}

Three infants who presented bilateral inguinal hernia and micropenis at birth were studied in our institute after they had been examined by other general physicians and pediatric endocrinologists. They were referred for molecular studies as a result of manifestations of genital ambiguity (Fig. 1) and laboratorial features indicative of $5 \alpha$-reductase deficiency. These patients had a normal 46,XY karyotype. There was no known consanguinity or history of the disease in any of the three families.

Patient 1 was a 6-month-old infant who had been raised as a female baby. When evaluated at 4 months of age, she presented penoscrotal hypospadias with pseudovagina, a short phallus $(1.0 \mathrm{~cm}$ in length), and bilateral testes that were palpable within the labioscrotal folds. Serum hormone concentrations were testosterone (T) $8.5 \mathrm{nmol} / 1$ (12.5-70 nmol/1), DHT $0.40 \mathrm{nmol} / 1$ (1-2.7 nmol/l), estradiol $18 \mathrm{pmol} / \mathrm{l}(<220 \mathrm{pmol} / \mathrm{l})$, androstenedione $1.09 \mathrm{nmol} /$ 1 (2.4-6.9 nmol/1), luteinizing hormone (LH) 0.8 IU/1 (0.5$7 \mathrm{IU} / \mathrm{l}$ ), and follicle-stimulating hormone (FSH) $2.5 \mathrm{IU} / 1$ (1-8 IU/l) (reference values in parenthesis). The T/DHT ratio after an human chorionic gonadotropin (hCG) stimulation test (1,000 IU/4 days) was 25 .

Patient 2 was an 8-year-old child who was raised as a girl. She was born with clitoromegaly, a blind-ending vaginal pouch and bilateral ovoid masses $(1.5 \times 2.0 \mathrm{~cm})$ in labia majora. Pelvic ultrasound showed no Mullerian structures. Serum hormone concentrations were T 24 nmol/l, estradiol 77 pmol/l, LH 9.0 IU/l, and FSH 11.0 IU/l (reference values as in patient 1 above). At 6 years of age, this patient was gonadectomized and submitted to genital reconstruction. Histopathology of the gonads revealed infantile testes. Because this patient was studied after gonadectomy had been performed, the diagnosis of $5 \alpha$-reductase deficiency was oriented on the basis of clinical findings and karyotype. The molecular screening of the AR gene did not detect abnormalities within the coding region (data not shown).

Patient 3 was a 3-year-old infant registered and reared as male. On physical examination, a microphallus in scarf (shawl) was observed. He also presented a penoscrotal hypospadias (with urethral meatus at the base of the phallus) and bilateral testes, which were palpable in the scrotum. Serum hormone concentrations were $\mathrm{T}$ $2.9 \mathrm{nmol} / 1$, androstenedione $1.25 \mathrm{nmol} / 1$, estradiol (not detectable), LH 2.1 IU/1, and FSH 0.9 IU/1 (reference values as in patient 1 above). He showed normal hormonal function; basal testosterone was $2.08 \mathrm{nmol} / 1$ (phallus $1.1 \mathrm{~cm}$ ), and poststimulation with hCG was $8.4 \mathrm{nmol} / \mathrm{l}$ (phallus $1.7 \mathrm{~cm}$ ). T/DHT ratio after stimulation with hCG was 32 .

The protocols for molecular studies were approved by the Ethical Committee for Investigation in Humans of our institute (INCMNSZ), and informed consent was obtained from the parents of each patient.

\section{Mutation detection}

The complete coding region of the SRD5A2 gene, including intron-exon boundaries, was amplified from genomic DNA extracted from peripheral blood leukocytes. Coding sequence abnormalities were assessed by exonspecific polymerase chain reaction (PCR) and singlestranded conformational polymorphism (SSCP) analysis followed by direct sequencing. PCR and SSCP analyses 
Fig. 1 External genitalia of three children $(46, X Y)$ with steroid $5 \alpha$-reductase 2 deficiency

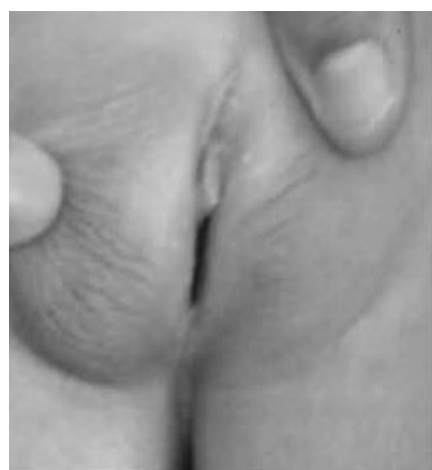

Patient 1

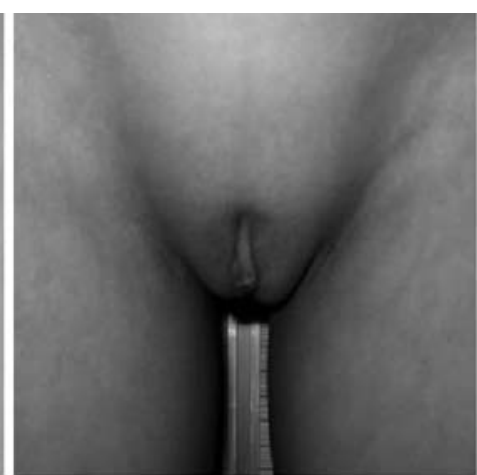

Patient 2

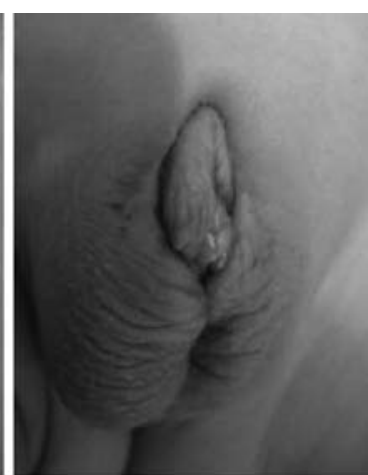

Patient 3 were carried out using specific primers and amplification conditions previously described (Vilchis et al. 1997; Chávez et al. 2000). PCR fragments showing an aberrant mobility pattern on SSCP were sequenced using the Thermosequenase $\left(\left[\alpha_{-}{ }^{33} \mathrm{P}\right] \mathrm{ddNTP}\right)$ Radiolabeled Terminator Cycle Sequencing kit (USB Co., Cleveland, OH, USA), as described elsewhere (Vilchis et al. 2000).

Site-directed mutagenesis

A commercial expression vector containing the human full-length SRD5A2 cDNA (pCMV-XL4, clone SC119922, (OriGene Technologies Inc., Rockville, MD, USA) was used as the template for E57Q, G85D, G115D, G183S, S210F, and P212X construction. These SRD5A2 mutants were constructed using the Gene Tailor site-directed mutagenesis system (Invitrogen, Life Technologies, Carlsbad, CA, USA), and highly purified primers according to the manufacturer's instructions. Mutagenic oligonucleotide primers 57F, $\left(5^{\prime}\right.$-gcgecgect ggttcctgcagcagctgcctt- $\left.3^{\prime}\right) ; \mathbf{5 7 R}, \quad\left(5^{\prime}\right.$-ctgcaggaaccaggcggcg cgggctggcag- $\left.3^{\prime}\right), \mathbf{8 5} \mathbf{F}\left(5^{\prime}\right.$-ccactgggacggtacttctggacctcttc$\left.3^{\prime}\right) ; \mathbf{8 5 R}\left(5^{\prime}\right.$-cagaagtaccgtcccaggtggeccgaagag- $\left.3^{\prime}\right), \quad \mathbf{1 1 5} \mathbf{F}$ $\left(5^{\prime}\right.$-ccagctatactcattctcagagacactgcc- $\left.3^{\prime}\right) ; \mathbf{1 1 5} \mathbf{R}\left(5^{\prime}\right.$-tctgagaat gagtatagctggataaggcct- $\left.3^{\prime}\right), \mathbf{1 8 3 F}\left(5^{\prime}\right.$-atcagctacaggattccacaa agtggcttg- $\left.3^{\prime}\right) ; \mathbf{1 8 3 R}\left(5^{\prime}\right.$-ttgtggaatcctgtagctgattctccagg- $\left.3^{\prime}\right)$, 210F ( $5^{\prime}$-ctatgectggccacttggttcctccag- $\left.3^{\prime}\right) ; 210 R\left(5^{\prime}\right.$-ccaa gtggccagggcatagccgatccattc- $\left.3^{\prime}\right)$ and 212F $\left(5^{\prime}\right.$-ccctggccactt ggtcctctgagcacttg- $\left.3^{\prime}\right) ; 212 \mathbf{R}\left(5^{\prime}\right.$-gagggaccaagtggccagggca tagccgat- $\left.3^{\prime}\right)$ were designed using the Primer $\mathrm{X}$ automated program (http://bioinformatics.org/primerx/documentation. html). PCR amplifications were performed with preheating at $95^{\circ} \mathrm{C}$ for $2 \mathrm{~min}$, followed by denaturation at $95^{\circ} \mathrm{C}$ for $30 \mathrm{~s}$, annealing at $55^{\circ} \mathrm{C}$ for $30 \mathrm{~s}$ and extension at $68^{\circ} \mathrm{C}$ for $8 \mathrm{~min}$ for 20 cycles. The mutated products were then transformed into DH5 $\alpha$-T1 competent cells. Positive clones were picked and sequenced to corroborate the site-directed mutations.
Transfections and $5 \alpha$-reductase assays

Human embryonic kidney cells (HEK-293) were maintained in Dulbecco's modified Eagle's medium (DMEM) supplemented with $10 \%$ stripped fetal calf serum and $100 \mathrm{U} / \mathrm{ml}$ penicillin and $100 \mu \mathrm{g} / \mathrm{ml}$ streptomycin. Transient transfections were performed in subconfluent $\mathrm{HEK}$ cells $\left(2 \times 10^{6}\right.$ cells/plate), which were maintained in $5 \% \mathrm{CO}_{2}$ at $37^{\circ} \mathrm{C}$. The wild-type and mutant plasmids were transfected into the cells at a concentration of $2.0 \mu \mathrm{g}$ per plate using the reagent Lipofectamine (Invitrogen Co., Carlsbad, CA, USA), according to the protocol provided by the manufacturer. Forty-eight hours later, the cells were rinsed with phosphate-buffered saline (PBS), harvested and processed for enzymatic assays. The $5 \alpha$-reductase activity was determined in cell extracts (sonicates) incubated at $\mathrm{pH} 5.5$ for $15 \mathrm{~min}$ in the presence of $8 \times 10^{5} \mathrm{dpm}$ of $\left[1,2,6,7-{ }^{3} \mathrm{H}(\mathrm{N})\right] \mathrm{T}$ (sp.act., $3.6 \mathrm{TBq} / \mathrm{mmol}$ ) and increased concentrations of unlabeled $\mathrm{T}(0.125-8.0 \mu \mathrm{mol} / \mathrm{l})$. All assay mixtures contained NADPH $(500 \mu \mathrm{mol} / \mathrm{l})$ as cofactor. After incubation, the steroids were extracted and analyzed by thin-layer chromatography (TLC), as previously described (Méndez et al. 1995). Measurement of $5 \alpha$ reductase activity was carried out in duplicate, and the results were expressed as nanomoles of DHT formed per milligram protein per hour.

\section{Results}

DNA molecular analyses disclosed the presence of six different allelic variants of the SRD5A2 gene. All three patients were identified as compound heterozygotes presenting with two distinct mutations in heterozygous form (Table 1). In each family, the parents were carriers of the corresponding allelic variant. The first patient presented a single base mutation $(547 \mathrm{G}>\mathrm{A}$ ) within exon 3 , changing codon 183 from glycine to serine (G183S), as well as a new 
dinucleotidic mutation $(634,635 \mathrm{CC}>\mathrm{TG})$ in exon 4 , changing codon 212 from CCA (proline) to TGA (premature termination signal) (Fig. 2). In the second case, a (346G $>$ A) substitution at codon 115 in exon 2 was responsible for a glycine to aspartic acid substitution. This patient also presented a novel substitution $(629 \mathrm{C}>\mathrm{T})$ at codon 210 in exon 4, which was responsible for a serine to phenylalanine (S210F) substitution (codon TTC instead of TCC). The third patient was a carrier for two mutations in exon 1 , including a novel $\mathrm{G} \rightarrow \mathrm{C}$ transversion at nucleotide 169, which changed codon 57 from glutamic acid to glutamine (E57Q), and a $\mathrm{G} \rightarrow \mathrm{A}$ transition at nucleotide 254, which changed codon 85 from glycine to aspartic acid (Fig. 2).

In order to ascertain the effect of these mutations upon enzyme activity, cDNA constructs encoding the normal and mutant enzymes were individually transfected into cultured HEK-293 cells, and cellular sonicates were assayed for $5 \alpha$-reductase activity. A representative saturation curve showing the ability of these SRD5A2 mutants to transform T into DHT is depicted in Fig. 3. As can be seen, the E57Q and G85D mutations reduced the enzyme activity to $\sim 25 \%$ and $<8 \%$ of normal, whereas mutations G115D, $\mathrm{S} 210 \mathrm{~F}$, and $\mathrm{P} 212 \mathrm{X}$ reduced the activity to $<1.0 \%$ of normal. In contrast, the G183S substitution displayed altered $5 \alpha$-reductase activity, as evidenced by the increased apparent $V_{\max }$ of 24.4 (nmol DHT per hour per milligram of cell sonicate protein) and an apparent $K_{\mathrm{m}}$ of $3.3 \mu \mathrm{M}$. Under similar experimental conditions, the $V_{\max }$ for the wild-type enzyme was $15.2(\mathrm{nmol} \mathrm{DHT} \cdot \mathrm{h} \cdot \mathrm{mg}$ protein) with a calculated $K_{\mathrm{m}}$ of $1.1 \mu \mathrm{M}$.

\section{Discussion}

In this study, we established the molecular diagnosis of steroid $5 \alpha$-reductase 2 deficiency in three children of Mexican origin with 46,XY DSD. Two genic variants of SRD5A2, including a new allelic variant, were detected in each individual, whereas the segregation pattern was consistent with the autosomal recessive character of this disorder. Despite the increased number of SRD5A2

Table 1 SRD5A2 gene mutations in three compound heterozygous patients

\begin{tabular}{llllllllll}
\hline Patients & Age years & Sex of rearing & Location & Nucleotide & Base change & aa change & Mutation & Type & Allele \\
\hline 1 & 0.5 & Female & Exon 3 & 547 & GGT $\rightarrow$ AGT & Gly $\rightarrow$ Ser & G183S & Missense & Maternal \\
& & & Exon 4 & 634,635 & CCA $\rightarrow$ TGA & Pro $\rightarrow$ stop & P212X & Nonsense & Paternal \\
2 & \multirow{2}{*}{8} & Female & Exon 2 & 346 & GGC $\rightarrow$ GAC & Gly $\rightarrow$ Asp & G115D & Missense & Maternal \\
& & & Exon 4 & 629 & TCC $\rightarrow$ TTC & Ser $\rightarrow$ Phe & S210F & Missense & Paternal \\
3 & \multirow{2}{*}{3} & Male & Exon 1 & 169 & GAG $\rightarrow$ CAG & Glu $\rightarrow$ Gln & E57Q & Missense & Maternal \\
& & & Exon 1 & 254 & GGC $\rightarrow$ GAC & Gly $\rightarrow$ Asp & G85D & Missense & Paternal \\
\hline
\end{tabular}

$a a$ amino acid

a Novel mutation

Fig. 2 Sequencing analysis of SRD5A2 showing part of the mutated exons in three patients with deficiency of $5 \alpha$-reductase. The affected individuals had the heterozygous mutations Pro212stop/Gly183Ser (patient 1), Ser210Phe/Gly115Asp (patient 2), and Gly85Asp/ Glu57Gln (patient 3), which were inherited from their parents. Three new allelic variants of SRD5A2 are indicated (asterisk)
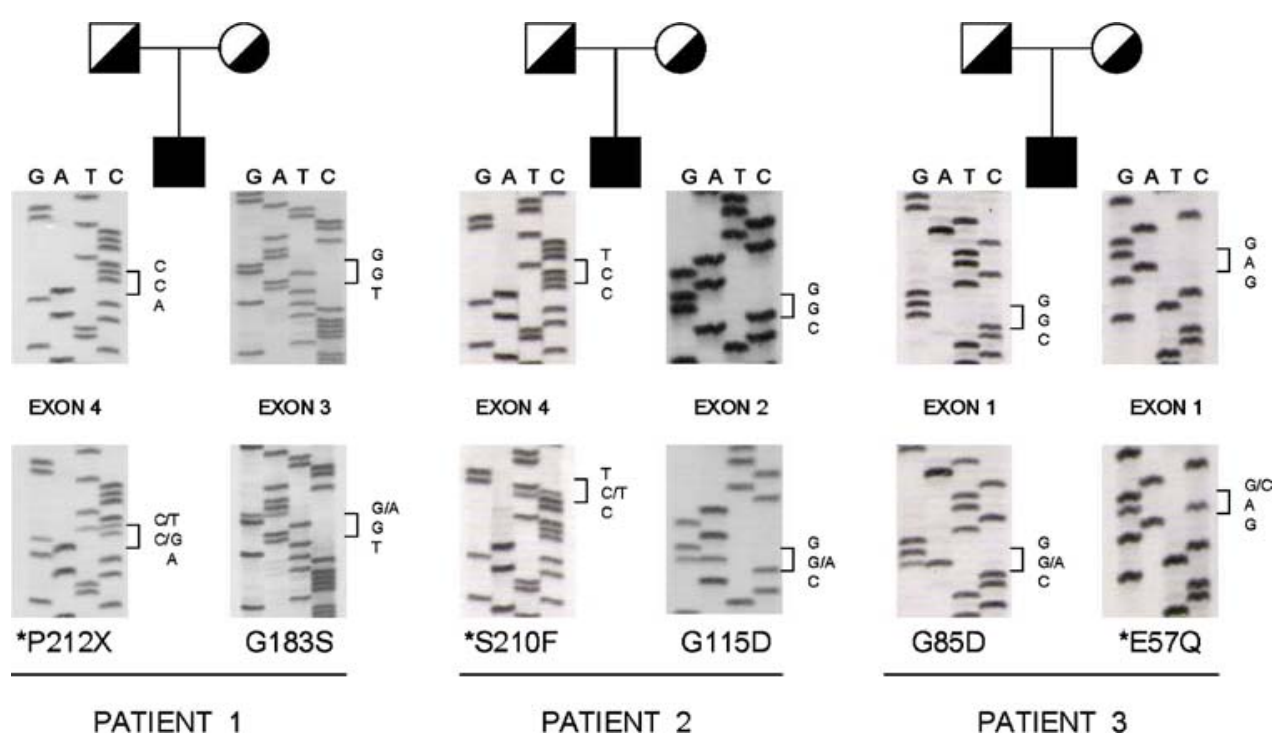


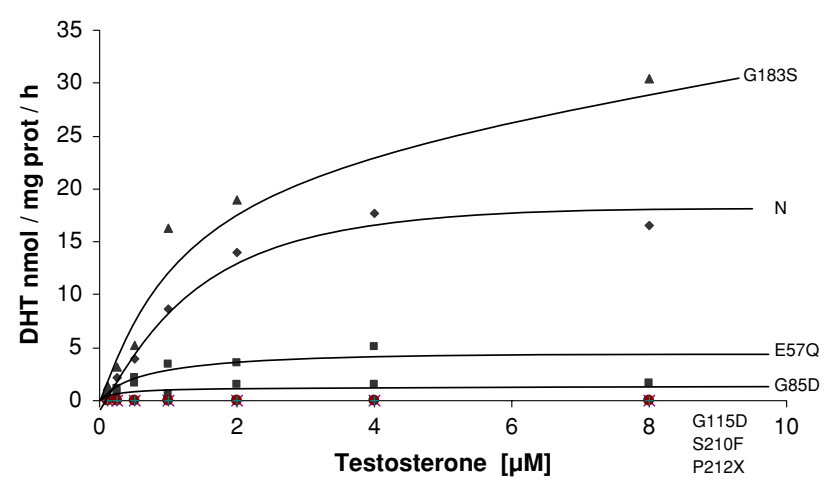

Fig. 3 Expression analysis of normal and mutant $5 \alpha$-reductase type 2 complementary DNAs (cDNAs). Enzyme activity was assessed in vitro at $\mathrm{pH} 5.5$ using cellular sonicates from human embryonic kidney (HEK-293) cells, which were transfected with expression vectors containing the normal or the indicated SRD5A2 substitution mutations. Assays were carried out for $15 \mathrm{~min}$ at $37^{\circ} \mathrm{C}$ in the presence of $500 \mu \mathrm{M}$ of nicotinamide adenine dinucleotide phosphate, reduced (NADPH) as cofactor. The conversion of $\left[{ }^{3} \mathrm{H}\right]$ testosterone to $\left[{ }^{3} \mathrm{H}\right]$ dihydrotestosterone was monitored by thin-layer chromatography and radioactivity scanning. Substrate concentration $(\mu \mathrm{M})$ versus formed $5 \alpha$-dihydrotestosterone (DHT) $(\mathrm{nmol} / \mathrm{mg}$ protein/h) is plotted

mutations identified, a reliable genotype-phenotype correlation has not been established, and individuals with the same molecular defect may exhibit different phenotypes. It is very likely that the mutations described here may account for the masculinization defects of our patients. Of the six alterations described, all but one were missense mutations that lead to amino acid replacement. In the three mutations previously reported, the affected residue was always glycine; two of these, Gly183 $\rightarrow$ Ser and Gly115 $\rightarrow$ Asp, have been found predominantly in subjects from Latin American countries such as Brazil, Mexico, and Dominican Republic (Thigpen et al. 1992a; Cai et al. 1996; Canto et al. 1997). Similarly, the Gly85 $\rightarrow$ Asp substitution was detected for the first time in a Mexican patient with penoscrotal hypospadias who also had a Gly115 $\rightarrow$ Asp substitution on the other allele (Vilchis et al. 2000). It was previously demonstrated that mutations at codon 183 gave rise to defective enzymes with decreased affinity for NADPH (Thigpen et al. 1992b; Wilson et al. 1993). Here, a Gly183 $\rightarrow$ Ser substitution together with a dinucleotidic mutation $634,635 \mathrm{CC}>\mathrm{TG}$ in exon 4 was detected in our first patient. In functional assays, the former mutation increased enzyme activity, as evidenced by the increased apparent $V_{\max }$ (Fig. 3), which strongly suggest a gain-of-function effect. This observation is supported by a previous study showing that some missense SRD5A2 mutations do not impair but increase the steroid $5 \alpha$-reductase activity (Makridakis et al. 2004).

On the other hand, the presence of this premature termination signal predicts the expression of a truncated 211amino acid protein with a large portion of the carboxyterminus deleted. Consistent with this, experimental evidence has shown that all nonsense mutations in SRD5A2 lead to the synthesis of proteins with no detectable enzyme activity (Wilson et al. 1996; Vilchis et al. 1997; Sasaki et al. 2003; Wang et al. 2004). Furthermore, the in vitro experiments of site-directed mutagenesis confirmed that the P212X mutant enzyme is devoided of catalytic activity (Fig. 3). Because the P212X/G183S mutations result in defective enzymes with distinct catalytic features, dysregulation in the synthesis of DHT during embryogenesis would be a plausible mechanism to explain the phenotypic alterations of this patient. In our population, the mutations at codon 212 appear to be highly recurrent. Nearly $40 \%$ of the subjects we studied were homozygous or heterozygous for Pro212 $\rightarrow$ Arg (Canto et al. 1997; Vilchis et al. 2000; Chávez et al. 2000). The prevalence of alterations at this site in Mexican patients could be the result of a founder gene effect. However, an alternative explanation could be that it may indicate the existence of mutational hot spots in this gene region. We have observed that of the 30 affected subjects, 23 of them $(\sim 75 \%)$ presented at least a homozygous or heterozygous mutation within exon 4, more specifically at codons 197, 203, 207, 212, and 227 (Canto et al.1997; Vilchis et al. 1997, 2000 and unpublished data). In addition, there is evidence that almost all mutations located between codons 197 and 230 render the enzyme completely inactive (Wilson et al. 1993). Consistent with this, here we found that the Ser210Phe mutation detected in patient 2 proves deleterious for the enzyme, since the substitution of serine for phenylalanine at position 210 leads to complete loss of activity. This new SRD5A2 variant, together with the P212stop mutation, is located within the gene region that encodes for a stretch of 21 amino acids (residues 206-226), which has been proposed as one of the four transmembrane domains of the enzyme (http://ca.expasy.org/uniprot/P31213). Thus, the recurrence of mutations at this particular site highlights somehow the importance of the fourth transmembrane domain as a key region for the correct functioning of $5 \alpha$-reductase type 2 . Taken together, these observations provide further evidence that exon 4 of SRD5A2 may be a prone site to inactivating mutations in the gene. Finally, the third new variant described here was a heterozygous Glu57 $\rightarrow$ Gln mutation detected in exon 1 of patient 3 . According to in vitro expression assays, this missense mutation may lead to the synthesis of an enzyme with partial catalytic activity. As the E57Q variant, the other single base mutations located at codon 85 also produced a mutant enzyme with decreased activity (Fig. 3). Thus, the residual activity achieved by the missense substitutions identified (E57Q and G85D) may explain in part the more male phenotype of this patient (Fig. 1).

In conclusion, we have identified the genetic alteration in three 46,XY infants who were compound heterozygous 
for SRD5A2 mutations. Six different mutations including three previously undescribed substitutions (E57Q, S210F, and $\mathrm{P} 212 \mathrm{X}$ ) are reported. These findings bring to 48 the total number of mutations in the SRD5A2 gene that impair DHT synthesis and cause male pseudohermaphroditism. We consider that the mutational analysis of the SRD5A2 is by far the most reliable tool for the diagnosis and molecular subclassification of steroid $5 \alpha$-reductase 2 deficiency, particularly in the case of newborns and minors with marked genital ambiguity.

Acknowledgments This work was supported in part by a project grant (44975) and a postgraduate studentship (to LR, Reg. 167215) from CONACyT (México).

\section{References}

Andersson S, Berman DM, Jenkins EP, Russell DW (1991) Deletion of steroid $5 \alpha$-reductase 2 gene in male pseudohermaphroditism. Nature 354:159-161

Cai L-Q, Zhu Y-S, Katz MD, Herrera C, Baéz J, DeFillo-Ricart M, Shackleton CHL, Imperato-McGinley J (1996) $5 \alpha$-Reductase-2 gene mutations in the Dominican Republic. J Clin Endocrinol Metab 81:1730-1735

Canto P, Vilchis F, Chávez B, Mutchinick O, Imperato-McGinley J, Pérez-Palacios G, Ulloa-Aguirre A, Méndez JP (1997) Mutations of the $5 \alpha$-reductase type 2 gene in eight Mexican patients from six different pedigrees with $5 \alpha$-reductase- 2 deficiency. Clin Endocrinol 46:155-160

Chávez B, Valdéz E, Vilchis F (2000) Uniparental disomy in steroid $5 \alpha$ reductase 2 deficiency. J Clin Endocrinol Metab 85:3147-3150

Fernández-Cancio M, Nistal M, Gracia R, Molina MA, Tovar JA, Esteban C, Carrascosa A, Audi L (2004a) Compound heterozygous mutations in the SRD5A2 gene exon 4 in a male pseudohermaphrodite patient of Chinese origin. J Androl 25:412-416

Fernández-Cancio M, Rodo J, Andaluz P, deOsaba MJM, RodríguezHierro F, Esteban C, Carrascosa A, Audi L (2004b) Clinical, biochemical and morphologic diagnostic markers in an infant male pseudohermaphrodite patient with compound heterozygous mutations (G115/R246W) in SRD5A2 gene. Horm Res 62:259-264

Griffin JE, McPhaul MJ, Russell DW, Wilson JD (2001) The androgen resistance syndromes: steroid $5 \alpha$-reductase 2 deficiency, testicular feminization, and related disorders. In: Scriver $\mathrm{CR}$ et al (eds) The metabolic and molecular bases of inherited disease. McGraw-Hill, New York, pp 4117-4146

Imperato-McGinley J, Guerrero L, Gautier T, Peterson RE (1974) Steroid $5 \alpha$-reductase deficiency in man: an inherited form of male pseudohermaphroditism. Science 186:1213-1215

Labrie F, Sugimoto Y, Luu-The V, Simard J, Lachance Y, Bachvarov D, Leblanc G, Durocher F, Paquet N (1992) Structure of human type II $5 \alpha$-reductase gene. Endocrinology 131:1571-1573

Makridakis N, Akalu A, Reichardt JKV (2004) Identification and characterization of somatic $5 \alpha$-reductase (SRD5A2) mutations in human prostate cancer tissue. Oncogene 23:7399-7405

Méndez JP, Ulloa-Aguirre A, Imperato-McGinley J, Brugmann A, Delfín M, Chávez B, Shackleton C, Kofman-Alfaro S, Pérez-
Palacios G (1995) Male pseudohermaphroditism due to primary $5 \alpha$-reductase deficiency: variation in gender identity reversal in seven Mexican patients from five different pedigrees. J Endocrinol Invest 18:205-213

Nicoleti A, Baldazzi L, Balsamo A, Barp L, Pirazzoli P, Gennari M, Radetti G, Cacciari E, Cicognni A (2005) SRD5A2 gene analysis in an Italian population of undermasculinized 46,XY subjects. Clin Endocrinol 63:375-380

Pérez-Palacios G, Chávez B, Méndez JP, Imperato-McGinley J, Ulloa-Aguirre A (1987) The syndromes of androgen resistance revisited. J Steroid Biochem 27:1101-1108

Russell DW, Berman DM, Bryant JT, Cala KM, Davis DL, Landrum CP, Prihoda JS, Silver RI, Thigpen AE, Wigley WC (1994) The molecular genetics of steroid $5 \alpha$-reductases. Rec Prog Horm Res 49:275-284

Russell DW, Wilson JD (1994) Steroid 5 $\alpha$-reductase: two genes two enzymes. Ann Rev Biochem 63:25-61

Sasaki G, Ogata T, Ishii T, Kosaki K, Sato S, Homma K, Takahashi T, Hasegawa T, Matsuo N (2003) Micropenis and the 5alphareductase-2 (SRD5A2) gene: mutation and V89L polymorphism analysis in 81 Japanese patients. J Clin Endocrinol Metab $88: 3431-3436$

Sinnecker GHG, Hiort O, Dibbelt L, Albers N, Dörr HG, Haub H, Heinrich U, Hemminghaus M, Hoepffner W, Holder M, Schnabel D, Krause K (1996) Phenotypic classification of male pseudohermaphroditism due to steroid $5 \alpha$-reductase 2 deficiency. Am J Med Genet 63:223-230

Thigpen AE, Davis DF, Gautier T, Imperato-McGinley J, Russell DW (1992a) The molecular basis of steroid $5 \alpha$-reductase deficiency in a large Dominican kindred. N Eng J Med 327:1216-1219

Thigpen AE, Davis DF, Milatovich A, Mendonca BB, ImperatoMcGinley J, Griffin JE, Francke V, Wilson JD, Russell DW (1992b) Molecular genetics of steroid $5 \alpha$-reductase 2 deficiency. J Clin Invest 90:799-809

Vilchis F, Canto P, Chávez B, Ulloa-Aguirre A, Méndez JP (1997) Molecular analysis of the $5 \alpha$-steroid reductase type 2 gene in a family with deficiency of the enzyme. Am J Med Genet 69:69-72

Vilchis F, Méndez JP, Canto P, Lieberman E, Chávez B (2000) Identification of missense mutations in the SRD5A2 gene from patients with steroid $5 \alpha$-reductase 2 deficiency. Clin Endocrinol 52:383-387

Walsh PC, Madden JD, Harrod MJ, Goldstein JL, MacDonald PC, Wilson J D (1974) Familial incomplete male pseudohermaphroditism, type 2: decreased dihydrotestosterone formation in pseudovaginal perineoscrotal hypospadias. N Eng J Med 291:944-949

Wang YP, Li Q, Xu JJ, Liu QJ, Wang WQ, Lin Y, Ma F, Chen TJ, Li SK, Shen Y (2004) Mutation analysis of five candidate genes in Chinese patients with hypospadias. Eur J Hum Genet 12:706-712

Wigley CW, Prihoda JS, Mowszowics I, Mendonca BB, New MI, Wilson JD, Russell DW (1994) Natural mutagenesis study of the human steroid $5 \alpha$-reductase 2 isozyme. Biochemistry 33:12651270

Wilson JD, Griffin JE, Russell DW (1993) Steroid $5 \alpha$-reductase 2 deficiency. Endocr Rev 14:577-593

Wilson JD, Griffin JE, Russell DW (1996) Steroid $5 \alpha$-reductase: one disorder/two enzymes/many unsolved problems. In: Bashin S et al (eds) Pharmacology, biology, and clinical applications of androgens. Wiley-Liss Inc., New York, pp 57-63 